\title{
PARA ONDE VAI O DIREITO À EDUCAÇÃO EM TEMPOS DE PANDEMIA?
}

\author{
Maria Abádia da Silva ${ }^{\mathrm{i}}$ \\ Edileuza Fernandes Silva ${ }^{\text {ii }}$
}

\begin{abstract}
Resumo: No contexto da pandemia, este artigo reflete acerca do ensino remoto e do direito à educação. Discutem-se ações e interesses de corporações e empresários do setor da educação na expansão de negócios; legislação e medidas de governos para oferta de ensino remoto e dados de pesquisa realizada com famílias. Parte-se de referências bibliográficas, documentos oficiais e questionários aplicados no Google Forms. Aponta-se que a regulação e a ordenação da oferta da educação remota favorecem a atuação do setor privado educacional e das tecnologias, despersonalizando o ensino e confrontando o direito constitucional à educação. Nesse contexto, famílias identificam desafios que podem obstaculizar a aprendizagem dos estudantes.
\end{abstract}

Palavras-chave: Covid-19; Direito à educação; Educação Básica; Ensino remoto; Tecnologias educacionais.

\section{WHERE DOES THE RIGHT TO EDUCATION GO IN PANDEMIC TIMES?}

\begin{abstract}
In the context of the pandemic, this paper reflects on remote teaching and on the right to education. It discusses the actions and interests of corporations and entrepreneurs in the education sector in business expansion; legislation and measures of governments to provide remote education; and research data conducted with families. The paper starts with bibliographic all references, official documents and questionnaires applied in Google Forms. It points out thattheregulationandorderingofthesupplyofremoteeducationfavorsthe performance of the private educational sector and of technologies, depersonalizing teaching and confronting the constitution al right to education. In this context, families identify challenges that may hinder students' learning, yet they recognize school as a field of possibilities.
\end{abstract}

Keywords: Covid-19; Right to education; Basic Education; Remote teaching; Educational technologies.

\section{Introdução}

$\mathrm{O}$ século XX foi marcado por mudanças sociais e do mundo do trabalho caracterizadas pelaTerceira Revolução Industrial ou Revolução Técnico-científica (HOBSBAWN, 1996). No início do século XXI prosperou o comando informacional e digital, denominado indústria 4.0, concebida para gerar um profundo salto tecnológico no mundo produtivo automatizado, robotizado e digital conduzido pelas Tecnologias de Informação e Comunicação (ANTUNES, 2018). Nesses processos emergiu uma nova fase de automação e modernização industrial, pelo uso da informática, da robotização e da demanda de força de trabalho mais qualificada, reverberando em novas formas de organização do trabalho e na exigência de um perfil de trabalhador para adequação a um modelo de produção mais flexível. Essas revoluções impactaram a vida das pessoas e as instituições sociais, em especial, escolas, institutos e instituições de educação superior públicas e privadas. 
No Brasil, desde os governos de Fernando Collor de Melo (1990-1992) e Fernando Henrique Cardoso (1995-2002), o setor empresarial educacional e os setores das tecnologias digitais e mídias sociais, da comunicação e telefonia têm se articulado politicamente para regulação e normatização da educação a distância na legislação, nos currículos escolares e na gestão de processos educacionais com a finalidade de expandir seus nichos de negócios e serviços, que desde 1996, estavam sob a provisão estatal. De olho nesse mercado, que representa conforme dados do censo escolar (INEP, 2020), cerca de 47,9 milhões de matrículas nas 180,6 mil escolas brasileiras, sendo 80\% dessas matrículas na rede pública, grupos empresariais ganharam força e apropriaram-se do discurso de melhoria da qualidade da educação pública, historicamente defendida pelos educadores, instituições, associações científicas e entidades do campo educacional.

No bojo desse movimento, o Governo Federal instituiu normativas como a Lei $n^{\circ} 11.079 / 2004$ que dispôs sobre licitação e contratação de parceria público-privada no âmbito da administração pública, o Parecer nº15/1997 (BRASIL/CEB, 1997) que dispôs sobre o ensino fundamental e médio (supletivo) e o Parecer n $n^{0}$ 41/2002 que instituiu as Diretrizes Curriculares Nacionais para a Educação a Distância na Educação de Jovens e Adultos e para a Educação Básica na etapa do Ensino Médio (BRASIL/CEB, 2002).

Nesse interregno, ações, atos jurídicos, discussões, compras e utilização de equipamentos e tecnologias passaram a exigir de gestores, secretários de educação, diretores e professores decisões para o atendimento à nova realidade social, educacional e tecnológica. Estavam em pauta: acesso à internet, aquisição de computadores, notebooks, banda larga, fibra ótica, smartfones, plataformas online, satélites, antenas, linha telefônica, televisão digital, tablets, aplicativos, ambientes virtuais de aprendizagem, programas, webcam, WhatsApp, sistemas operacionais, rede elétrica, entre outros. Essa realidade somada às históricas questões educacionais de garantia de acesso e permanência dos estudantes na escola com aprendizagem de todos torna ainda mais complexo o trabalho de diretores escolares e professores.

No entanto, é pelo trabalho que os seres humanos criativos, sociais e em constante mudança fazem a história nas condições reais e objetivas, nas relações dinâmicas entre as partes; buscam o sentido da vida, nas invenções, para transformar a si mesmos e aos outros (MARX; ENGELS, 1984). Nesse processo de produzir a si mesmo, o ser humano traz para o campo da realidade social sua atividade consciente, situada historicamente, que, por meio de instrumentos materiais e mentais objetivam sua racionalidade, subjetividade e sociabilidade. Compreender a relação dos seres humanos com o trabalho tornou-se relevante, pois são profissionais da educação que desenvolvem suas atividades teleológicas e transformadoras no trabalho pedagógico escolar, cerne da formação humana, posta em debate na educação a distância no contexto da pandemia do Covid-19. 
Em janeiro de 2020, na onda das tecnologias e redes sociais, dados do relatório da organização da sociedade civil brasileira criada em $2014\left(\right.$ Oxfam $\left.^{\mathrm{iii}}\right)$ apontam que senhores de Davos, "bilionários do mundo possuem uma riqueza maior do que 4,6 bilhões de pessoas, aproximadamente $60 \%$ da população global e prossegue, bilionários acumulam e concentram riquezas às custas do trabalho da população". Esses dados revelam que, mesmo com o desenvolvimento da ciência e da tecnologia, a "globalização produtiva, a lógica do sistema produtor de mercadorias vem convertendo a concorrência e a busca de produtividade num processo destrutivo que tem gerado uma imensa sociedade dos excluídos e dos precarizados" (ANTUNES, 2015, p. 214). Os avanços científicos e tecnológicos não beneficiam a todos em um modo de produção exploratório e desigual.

Nesse cenário de desigualdade social e econômica global, explodiu a pandemia do novo coronavírus (SARS-CoV-2), a Covid-19, doença causada pelo vírus com alto grau de letalidade, semelhante a outras epidemias, o contágio alcança, de maneiras distintas, pessoas, classes sociais, regiões e aldeias o que levou governos de todos os países afetados a adotarem políticas de isolamento social.

$\mathrm{Na}$ espreita, os mercadores da educação e das tecnologias aproveitam o contexto para a produção, circulação, consumo, distribuição e acumulação, visto que a saúde e a educação públicas são tomadas e inseridas no ramo de negócios privados com fins lucrativos. Isso ocorre em um contexto de forte reação no ensino, liderado pelo Movimento Escola sem Partido ${ }^{\text {iv }}$, que defende o discurso de escolas mais eficientes e receptivas no setor privado que as transformam, assim como aos estudantes, em bens de mercado (APPLE, 2003).

Em face dessas reflexões iniciais, este artigo busca refletir acerca do direito à educação diante da aceleração e utilização da educação a distância via plataformas e tecnologias no contexto da pandemia do coronavírus-Covid-19. Com esse intuito, três questões são suscitadas: como o setor empresarial aproveita as crises estruturais para expandir negócios no setor de serviços? Se a educação básica pública foi elevada a nicho de mercado, para onde foi o direito à educação? Que percepção as famílias que acompanham seus filhos em atividades escolares online têm sobre a escola?

A discussão ocorre a partir da legislação, de referenciais bibliográficos, do Decreto n. $^{\circ}$ 9.057/2017 que trata da educação a distância, da Portaria n ${ }^{0}$ 343/2020 que dispõe sobre a substituição das aulas presenciais por aulas em meios digitais enquanto durar a situação de pandemia, e de questionários respondidos no período de 10 a 20 de abril de 2020, usando a ferramenta Google Forms.

$\mathrm{O}$ artigo estrutura-se em três seções. Na primeira, busca-se explicitar ações e movimentos do governo federal, empresários e mercadores da educação e das tecnologias antes e durante o surgimento da pandemia do Covid-19. Na segunda, problematizam-se questões regulatórias, normativas e pedagógicas à luz do Decreto no 9.057/2017 que trata da educação a distância (EaD) e da Portaria $n^{0}$ 343/2020 que flexibiliza os 200 dias letivos e autoriza a oferta de disciplinas presenciais na modalidade a distância para 
estudantes de educação básica pública. Na terceira, problematiza-se o direito educacional presente na lei, mas, driblado e encurtado pelas desigualdades estruturais, digitais e sociais. Discute-se, também, percepções de famílias que acompanharam seus filhos em atividades mediadas pelas tecnologias e responderam o questionário no Google Forms.

\section{O movimento dos governos, empresários e corporações no contexto do Covid-19}

No Brasil, em termos econômicos, tem se fortalecido o movimento de expansão de parcerias público-privadas nos serviços e na administração pública, de presença de mercadores e corporações tecnológicas e de comunicação na formulação, direção e execução das políticas de saúde e educação, tornando-as nichos de exploração mercantil lucrativo. Esse movimento encontrou na pandemia do Covid19, oportunidade de expandir negócios e atividades lucrativas.

A partir de fevereiro de 2020, a pandemia do Covid-19 explodiu o contágio em escala planetária, revelando os limites dos sistemas de saúde dos países (HARVEY, 2020; SOARES, 2020) e indicando que a economia e as políticas públicas de saúde possuem elementos comuns, articulados e interdependentes em todo o mundo. Entre a perplexidade e os sinais de propagação da doença, governos, médicos e autoridades sanitárias recomendaram, a fim de conter a disseminação do vírus: a criação de barreiras à circulação e aglomeração de pessoas; estímulo ao home office, trabalho remoto; fechamento de fronteiras entre os países; confinamento das pessoas em casa, isolado-as socialmente. Fique em casa tornou-se slogan comum. No Brasil, inicialmente, uma parte da população permaneceu confinada em casa, a outra parte, desassistida de programas dos governos, mesmo correndo riscos de contágio, voltou aos espaços de trabalho formais e informais.

Diante da insuficiência e dos limites das políticas para grupos sociais vulneráveis, o Estado neoliberal atua como mão invisível para salvar os capitalistas. Os financistas, investidores e mercadores, exigem medidas de alento para a sobrevivência de seus negócios, transferência de renda para empresas e bancos, setores aéreo, da indústria, de comércio e de serviços. As indústrias farmacêutica, biomédia, química e tecnológica agarraram as oportunidades de prosperar, pois remédios e vacinas exigem investimentos em pesquisas, laboratórios, centros de estudos e universidades. $\mathrm{Na}$ prática, não funcionaram os dispositivos neoliberais de livre mercado e concorrência, ao contrário, recorreu-se à intervenção do Estado capitalista para proteger suas atividades e o mercado, reforçando os argumentos de Mariutti (2020) de que Estado e mercado não são antagônicos, operam juntos.

No Brasil, o Governo Federal, por meio do Ministério da Economia, promulgou o Decreto Legislativo $\mathrm{n}^{\mathrm{o}}$ 6, de 20 de março de 2020, que instituiu o estado de Calamidade Pública e a Medida Provisória $\mathrm{n}^{\circ} 927$ que autorizou medidas restritivas dos direitos trabalhistas e de proteção de empresários. 
Publicou ainda, a Medida Provisória $n^{0} 936$ de 01 abril de 2020 modificando as relações trabalhistas, instituindo o Programa Emergencial de Manutenção de Emprego e Rendav com três medidas: benefício emergencial de preservação do emprego e da renda, redução proporcional temporária de jornada com redução de salários e suspensão temporária do contrato de trabalho.

Durante os meses da pandemia, o sistema metabólico de reprodução do capital freou o frenético ritmo e velocidade da extração de mais-valia dos trabalhadores em distintas regiões e evidenciou o paradoxo: por um lado, setores das indústrias, comércio, agronegócio e serviços bradavam e exigiam o retorno dos trabalhadores aos seus postos de trabalho, por outro, os servidores públicos passaram a trabalhar em home office, enquanto parte dos trabalhadores do setor privado continuou em seus trabalhos sujeitos aos riscos de contágio. Além disso, outros trabalhadores, informais, desempregados e desassistidos, permaneciam cada vez mais excluídos dos direitos sociais e trabalhistas (ALVES, 2020; ANTUNES, 2018; SENNETT, 2006).

A multiplicação do Covid-19 entre os países e pessoas revelada pelas tecnologias digitais, meios televisivos e redes sociais expôs em números e imagens as pessoas contaminadas e desassistidas, a insuficiência de hospitais, famílias imersas em privações, desvelando o caráter de classe do Estado brasileiro.

\section{Questões regulatórias, normativas e pedagógicas. E o direito a Educação?}

Parte-se do entendimento de que elementos da conjuntura política 2016-2020 estão articulados com as frações e as forças políticas dos setores educacional e de tecnologias e mídias, com foco nas pressões para a abertura de nicho de mercado na educação básica pública.

Desde 2016, a Emenda Constitucional $n^{\circ}$ 95/2016, que congelou por vinte anos os recursos públicos para Saúde e Educação, vem asfixiando e travando a pesquisa científica nas universidades e institutos públicos, além de projetos destinados a assegurar o cumprimento das políticas sociais. O princípio subjacente à Emenda amarra, restringe e flexibiliza as instituições científicas e acadêmicas e de pesquisa para que disputem recursos de empresas,conformando, assim, a ciência com a força produtiva do capital. Nos anos seguintes, essa mesma Emenda contingenciou e provocou a redução progressiva dos recursos do orçamento federal para as universidades públicas ${ }^{\mathrm{vi}}$ e Institutos Federais de Ciência e Tecnologia. No entanto, a Lei de Diretrizes e Bases da Educação Nacional nº 9.394/96 prescreve:

a) no artigo $5^{\circ}, \S 5^{\circ}$, de forma indireta, que "para o cumprimento da obrigatoriedade de ensino, o Poder Público criará formas alternativas de acesso aos diferentes níveis de ensino, independentemente da escolarização anterior"; 
b) no artigo $32, \S 4^{\circ}$ que "o ensino fundamental será presencial, sendo o ensino a distância utilizado como complementação da aprendizagem ou em situações emergenciais". O Decreto Federal $\mathrm{n}^{\circ}$ 9.057, de 2017, dispõe no artigo $9^{\circ}$, que essa oferta de ensino à distância no ensino fundamental, refere-se ao atendimento a pessoas impedidas, por motivo de saúde, de acompanhar o ensino presencial; que se encontrem no exterior, por qualquer motivo; que vivam em localidades que não possuam rede regular de atendimento escolar presencial; que sejam transferidas compulsoriamente para regiões de difícil acesso, incluídas as missões localizadas em regiões de fronteira; ou que estejam em situação de privação de liberdade;

c) no artigo 80, que "o poder público incentivará o desenvolvimento e a veiculação de programas de ensino a distância, em todos os níveis e modalidades de ensino e de educação continuada";

d) no artigo $80, \S 1^{\circ}$ que "a educação a distância, organizada com abertura e regime especiais, será oferecida por instituições especificamente credenciadas pela União”.

É também em 2016, que o CNE/CEB define a Educação a Distância como modo de "ensinoaprendizagem mediado por tecnologias que permitem a atuação direta do professor e do aluno em ambientes físicos diferentes, na Resolução $n^{\circ} 1$ publicada em fevereiro, em consonância com o disposto no art. 80 da Lei $n^{\circ}$ 9.394/96 e com o Decreto $n^{\circ}$ 5.622/2005". Essas manifestações para a expansão da educação a distância foram incorporadas ao Parecer CNE-CEB n ${ }^{\circ} 13$ de 2015 e à Resolução CNE/CEB $\mathrm{n}^{\circ} 1$ de 2016 ,

considerando a multiplicidade de plataformas, meios e mídias como do Ambiente Virtual de Aprendizagem (AVA), transmissão de aulas via satélite, internet, videoaulas, telefonia celular, redes sociais, aplicativos mobile learning, TV digital, rádio, impresso e outros que compõem o arsenal de Tecnologias da Informação e Comunicação (TIC), que podem ser apropriadas e adequadas a diferentes modelos e formatos de mediação pedagógica, a fim de garantir que a mesma atenda plenamente a nova localidade em que pretende atuar, sendo capaz de viabilizar a transmissão e mediação de conteúdos pelos meios compatíveis com a realidade da região pretendida (BRASIL, CNE-CEB nº 1, 2016).

Ainda no governo Michel Temer (agosto 2016-2019), foi sancionado o Decreto nº 9.057/2017 que dispõe sobre a educação a distância na educação básica e superior, um nítido sinal de abertura deste nicho para os empresários educacionais. Cabe registrar ainda que 2016 e 2017 foram anos de intensa disputa de projetos inter grupos econômicos, banqueiros investidores, financistas e redes políticas para elevar a educação ao campo dos serviços públicos não estatais.

Para fins deste Decreto, considera-se: educação a distância, modalidade educacional desenvolvida em espaços e tempos diversos, com utilização de meios e tecnologias de informação e comunicação nos processos de ensino e aprendizagem, mediados por profissional qualificado (art. $1^{\circ}$ ); que a educação básica e a educação superior poderão ser ofertadas na modalidade a distância $\left(\operatorname{art.~} 2^{\circ}\right)$; que atividades 
presenciais, tutorias, avaliações, estágios, práticas profissionais e de laboratório e defesa de trabalhos, previstas nos projetos pedagógicos das instituições de ensino e do curso, podem ser realizadas na própria instituição, em polos de educação a distância ou em ambiente profissional, conforme Diretrizes Curriculares Nacionais (art. $3^{\circ}$ ); que compete aos sistemas de ensino estaduais, municipais e distrital autorizar os cursos e o funcionamento de instituições de educação na modalidade a distância no ensino fundamental e ensino médio (art. $\left.4^{\circ}\right)$.

O entendimento do Decreto $\mathrm{n}^{\circ}$ 9.057/2017 exige recuperar os fundamentos teóricos e filosóficos que estão interligados com o modo de funcionamento de reprodução do capital em tempos de crise estrutural. Observe-se que o $2^{\circ}$ artigo expressa que a educação básica e a educação superior poderão ser ofertadas na modalidade a distância; o $1^{\circ}$ artigo anuncia um conceito de educação a distância, os meios para mediação didático-pedagógica e quem está habilitado para mediá-lo nos processos de ensino e aprendizagem; os artigos $3^{\circ}$ e $8^{\circ}$ indicam quem faz a regulação e a normatização da EaD; e o artigo $4^{\circ}$ descreve as atividades, locais e instituições que estão autorizadas a ofertar tal modalidade.

Em 2002, o Conselho Nacional de Educação - Câmara da Educação Básica ${ }^{\text {vii }}$ (CNE/CEB 41/2002) normatizou a oferta do ensino a distância para o ensino médio.

O que esses atos normativos significam para a educação básica pública? Que o governo federal modificou a LDB $n^{\circ}$ 9.394/96 e passou a permitir, por enquanto, no ensino médio, que $20 \%$ da carga horária sejam ofertadas na modalidade a distância. Significa também que, atento aos propósitos do setor privado que via amplas potencialidades nessa etapa, abre-se um nicho de mercado de equipamentos, plataformas, aplicativos, entre outros, a ser explorado pelos setores educacional, de tecnologia, de telefonia, entre outros.

Nesse processo gradual de abertura da educação ao mercado, dois movimentos interligados operaram transformações sociais: um, expresso na avalanche de tecnologias e mídias digitais e online, pressionam e alteram ainda mais a vida das pessoas, o trabalho, as formas de comunicação, de transporte, de organização das escolas, institutos e universidades públicas. De forma muito rápida, fustigou-se a velha burocracia dos sistemas de ensino, das escolas, dos institutos e universidades, bem como o trabalho pedagógico, a pesquisa científica, enfim, e fomos tomados pelos avanços tecnológicos com mudanças estruturais.

O outro movimento tem sido conduzido pelos governos conservadores com os preceitos neoliberais encobertos ou visíveis, interligados e conectados à educação básica pública tornando-a consoante com a formação de seres humanos que deseja, para a reprodução de um modelo social desigual e de exploração que caracteriza um projeto social e ideológico. Assim, no interior dos dois movimentos localizam-se ações, atos e legislação federal com vistas a estender a educação a distancia a toda a educação básica, um nicho de mercado a ser explorado pelos mercadores que atuam e se movimentam 
dentro da ordem constitucional com o intuito de atingir lucros, pois, da produção material, circulação e consumo, distribuição e reinvestimento provêm a acumulação do capital em diferentes tempo-espaço históricos (MARX, 2008).

Esses interesses estão na contramão do projeto democrático de educação que considera a diversidade social, cultural, econômica dos que frequentam a escola pública, bem como a necessidade de condições que favorecem a garantia do direito subjetivo prescrito. São interesses que não levam em conta as diferenças entre redes de ensino pública e privada e as condições sociais e econômicas desiguais dos estudantes, suas idades, ritmos e necessidades diversas.

Em face disso, questiona-se: que relação pode haver entre a oferta de educação utilizando meios e tecnologias de informação e comunicação e os interesses de grupos ligados ao comércio de equipamentos tecnológicos e serviços? Em que medida a adoção de "aulas e atividades virtuais", computando carga horária da educação básica, assegura o previsto nos incisos I e VII do artigo 206 da Constituição Federal e incisos I e IX do artigo $3^{\circ}$ da Lei das Diretrizes e Bases da Educação Nacional: garantia da igualdade de acesso e permanência na educação e dos padrões de qualidade no ensino, para todos/as os/as estudantes da rede pública?

É no contexto da pandemia do Covid-19 e de atuação de corporações tecnológicas e de informática com expertise mercantil para a oferta do ensino remoto que se intenta analisar como essa oferta implica a garantia do direito à educação em igualdade de condições para todos. Para isso, exige-se apontar na sua constituição histórica, os fundamentos da política para a educação básica pública no país. O primeiro fundamento localiza-se na formação e na organização social brasileiras marcadas por concentração de renda, latifúndio, exportação de commodities, divisão em classes sociais, exploração da força de trabalho, grupos ou famílias que ostentam riquezas, privilégios e propriedades. Na gênese da formação social, determinadas famílias oligárquicas, grupos conservadores e proprietários da terra expressaram profundo desprezo pela escolarização da população, pela pesquisa e ciência (FERNANDES, 2006; RIBEIRO, 1982). Esses grupos oligárquicos, tornaram-se elites dirigentes acostumadas a importar padrões europeus a ponto de enriquecer e menosprezar qualquer provisão de recursos financeiros para a educação básica da população.

A sociedade brasileira erguida sob a cultura patriarcal, dominação e superioridade do homem tem, na sua gênese, a exploração da força de trabalho, a concentração da propriedade, a ostentação de privilégios pelas elites familiares que vivem com subsídios e prebendas do Estado. Desde o início, Estado e mercado operam para a produção, circulação, distribuição e reprodução do capital e, neste movimento, estabelecem interrelações com o setor empresarial com fins lucrativos e o setor religioso caritativo ou filantrópico para empreender negócios econômicos. 
O segundo fundamento refere-se aos determinantes econômicos e sociais marcados pelo trabalho dos africanos escravizados, desumanizados, expropriados e coisificados e sem nenhum direito. Esses, no entanto, eram levados à justiça quando cometiam algum delito (CURY, 2020). Ora eram vistos como objeto, coisa, ora como sujeitos de direito. Em 1888, novamente sem direitos, foram lançados como força de trabalho a ser explorada pelos proprietários nas cidades ou no campo. Um século depois, (1988) resultado de muitas lutas, os direitos sociais foram inscritos na Constituição Federal. Porém, logo, grupos conservadores exigiam reformas para funcionamento do capital, alterações na legislação trabalhista, retirada de direitos sociais fizeram emergir a exclusão digital e social ampliadas.

Ao apreender o processo histórico de organização e formação social, política e jurídica encontrase o terceiro fundamento que tem como marca distintiva a apropriação da coisa pública e seu uso como um bem privado, particular. Ao percorrer a história da educação brasileira pode-se constatar um núcleo duro composto por governos, empresários e religiosos ávidos por usurpar a riqueza alheia em proveito particular. Diante de sinais de crise eles se renovam, fazem acordos e alianças para preservar interesses.

$\mathrm{O}$ quarto fundamento encontra-se nas relações construídas entre Estado e Mercado frente às demandas de produção, circulação, distribuição e acumulação no funcionamento do capital em uma constante tensão entre poder político e donos do dinheiro, que não são antagônicos, mas operam unidos. Aqui, o direito à propriedade privada reproduz as dinastias familiares e o individualismo e serve como símbolo do esforço individual de fazer boas escolhas. As forças políticas, religiosas, conservadoras e neoliberais disputam a primazia na definição das finalidades da educação operando para moldar "e criar um novo tipo de homem, capaz de comportar-se como empresa" (MAURITTI, 2019, p. 24), o autoempreendedor.

Também, nas circunstâncias histórias, os privatistas e publicistas disputam a educação (CUNHA, 2017). Para os publicistas, o direito à educação tem raízes na compreensão dos valores democráticos e republicanos de formação humana das sociedades modernas. E para os distintos grupos de privatistas e de neoliberais (empresários, mercadores, investidores e filantropos) o mercado ordena as práticas sociais, a concorrência e atenua os riscos. Portanto, no movimento da economia, em geral, estão três distintos grupos privatistas: liberais, "novos liberais" e neoliberais (MAURITTI, 2019, p. 21), que se apresentam no Ministério da Educação, no Conselho Nacional de Educação, nas associações dos empresários da educação privada para a elaboração, a regulação e a ordenação da política educacional. É neste movimento contraditório, dialético e dinâmico que vão propagando as finalidades da educação.

O quinto fundamento assenta-se na desvalorização dos professores e da escola pública, pela primazia do autoritarismo, hierarquia de classe, dispositivos disciplinares, premiação e punição, vigilância, obediência, sujeição e distintas formas de controle estatal, simbólico ou religioso. Na base desse fundamento está a distribuição e o direito aos bens culturais que, para o funcionamento do capital, 
são desigualmente distribuídos. Forjam-se níveis de necessidades, vontades e desejos por região, grupos sociais, renda e formação escolar ou acadêmica, com a finalidade de, nas contradições, atribuir mais valor aos produtos. Como o direito à educação vira um produto? Como driblar, encurtar e restringir este direito dentro da ordem jurídica constitucional?

Prosseguindo nessa linha, depois de inúmeras manifestações, marchas e lutas dos movimentos sociais, associações científicas e entidades para instituir na Constituição Federal de 1988 o direito à educação, indaga-se: com a autorização do enisno remoto preconizado pelo Conselho Nacional de Educação para a educação básica, como garantir o direito à educação? Uma situação de excepcionalidade em razão do Covid-19, pode alterar o direito à educação?

Observe que o Conselho Nacional de Educação, pela Portaria 343/2020, autorizou a substituição de aulas presenciais por ensino remoto entendido como conjunto de atividades, vídeos, leituras, tarefas, interação on-line, manuais disponíveis para aprendizagem, produção de materiais, avaliação diagnóstica, atividades de conteúdo, uso de tablets, notebooks e computadores pelo menos até o fim da pandemia para toda a educação básica.

Nesse contexto, o setor empresarial, que vinha pressionando para a abertura de negócios na cadeia tecnológica on-line e digital, usou o álibi da pandemia do coronavírus para, dentro da ordem constitucional, atuar e vender plataformas, serviços e materiais curriculares aos governos a fim de remediar a oferta da educação básica pública. Enquanto os secretários de educação e gestores estaduais e municipais insistem em preparar as famílias, capacitar os professores e as escolas, sob a retórica de fortalecer os vínculos, atribui-se às famílias a responsabilidade por parte das tarefas de formação escolar no âmbito domiciliar.

No entanto, desconsideram-se as estruturas perversas de desigualdades, empobrecimento familiar, condições precárias de habitação, desemprego, famílias sem nenhuma renda, acesso à internet banda larga, e ausência decomputadores. Além disso, professores, diretores, servidores e discentes precisam de tempo para formação tecnológica e de equipamentos funcionando nas duas pontas. Enfim, o improviso de arranjos para parecer que os estudantes estão tendo acesso aos conteúdos curriculares configura um mecanismo para driblar e restringir o direito à educação.

Então, o que está oculto? A abertura irrestrita do mercado privado lucrativo - já consolidado na educação superior no país - à educação básica pública dentro da ordem constitucional. Esses mercadores da educação calculam a expansão da produção, consumo e circulação e avançam na venda de serviços e educação a distância. Essa posição pôde ser percebida no evento "Educação frente à pandemia" realizado em 8 de abril de 2020, pelo Conselho Nacional de Educação, Banco Mundial, Todos pela Educação, com a participação da União Nacional dos Dirigentes Municipais de Educação (Undime) e do Conselho Nacional de Secretários da Educação (Consed). Naquela ocasião, a defesa era pela educação remota, 
reinventar a educação com as tecnologias e copiar dos países o que eles estão fazendo. Os promotores do evento se posicionam com expertise e concepções de ensino remoto que não consideram as desigualdades estruturais e sociais do Brasil e consideram as tecnologias como um fim em si mesmas. Nenhuma palavra foi mencionada sobre mais recursos públicos para impulsionar aprendizagens e metodologias de ensino, e sobre as travas da Emenda Constitucional 95/2016 que define um teto por vinte anos nos investimentos públicos para saúde e educação, aniquilando o orçamento das universidades e dos institutos federais públicos. Sim, faz falta o dinheiro para pesquisas, para bolsas de estudos, para compra de insumos, programas e equipamentos. E mais, só equipamentos não bastam, exige-se inteligência científica, financiamento público, condições de trabalho, profissionais qualificados, respeito à autoria dos professores e adequada remuneração salarial. Isto sim, são atribuições e função do Estado.

Assim, o direito educacional vem sendo corroído quando: (i) crianças e jovens de famílias empobrecidas estão impedidas de frequentar a escola e não têm condições de estudar em casa; (ii) crianças e jovens pobres estão nas ruas sem amparo; (iii) pouquíssimas famílias têm acesso à internet, muitas vivem em regiões sem a oferta desse serviço público, nem infraestrutura; (iv) ocorre restrição de acesso ao conhecimento historicamente produzido, aos conteúdos científicos, a outras visões de mundo, mediados por professores, (v) crianças e jovens estão privadas das relações sociais, afetivas e relacionais e que favorecem a elevação e o desenvolvimento de suas capacidades cognitivas, (vi) os governos e autoridades políticas dissimulam que estão cumprindo o direito, mas atuam para driblar o acesso ao conhecimento, à ciência, às artes, à filosofia e a visões de mundo, (vii) os governos sabem que, quanto mais tecnologias on-line e digitais, mais cálculos são arrolados pelos mercadores do ensino, pois esses desenlaçam outras cadeias produtivas, geram lucros, mas também explicitam os estruturais processos de exclusão social e digitais na sociedade brasileira.

No entanto, a excepcionalidade não muda o direito à educação, cláusula pétrea da Constituição Federal de 1988, pois estamos no Estado Democrático de Direito. No período de exceção do Covid-19, exige-se dos governos garantir e preservar o direito a Educação; adotar medidas para manter vínculos afetivos, proteger os estudantes, professores e trabalhadores da educação; munir-se de dados científicos; fortalecer a pesquisa científica e os pesquisadores; zelar pela difusão e transparência de informações; prover produtos de consumo e equipamentos necessários; utilizar tecnologias para melhorar a vida das pessoas; praticar a solidariedade; cumprir e reinventar formas, ferramentas, protocolos que preservem a vida; fornecer alimentos aos desabrigados e desassistidos até que a situação se normalize.

Dos movimentos sociais, populares e associações científicas exige-se que atuem para que o direito à educação não fique na forma jurídica presente, na letra da lei, distante das famílias e dos estudantes, mas que o direito de acessibilidade às tecnologias digitais e o direito a Educação sejam para todos e todas. 


\section{O ensino remoto mediado por tecnologias da informação e comunicação na educação básica: percepções das famílias}

Diante de um cenário de contigenciamento de recursos públicos, perdas de direitos sociais e trabalhistas, aumento do desemprego, adoção de práticas gerencialistas na gestão pública, entre outros, o Brasil é atingido pela pandemia do Covid-19. Inúmeras instituições da sociedade tiveram que alterar suas rotinas de trabalho ou suspendê-las, entre elas as instituições de educação básica pública.

Ao longo de anos proclamadas por governantes e grupos conservadores como "fracassos completos" pelos fracos desempenhos dos estudantes, medidos por exames em larga escala - nacionais e internacionais -, pela violência e pelo que denominam ideologização da juventude, essas instituições retornam à cena com protagonismo que oscila entre a garantia do direito de crianças, jovens e adultos à educação básica e a preocupação de governos com resultados medidos por avaliações em larga escala e cumprimento de calendário escolar.

Com esse intuito, em março de 2020, o Ministério da Educação publicou a Portaria no 343 de 17 de março de 2020 que dispõe sobre a substituição das aulas presenciais por aulas em meios digitais enquanto durar a situação de pandemia do coronavírus, para a discussão neste artigo, importam os artigos relacionados à educação básica, como se segue:

Art. $1^{\circ}$ Autorizar, em caráter excepcional, a substituição das disciplinas presenciais, em andamento, por aulas que utilizem meios e tecnologias de informação e comunicação, nos limites estabelecidos pela legislação em vigor. [...]

$\S 2^{\circ}$ Será de responsabilidade das instituições a definição das disciplinas que poderão ser substituídas, a disponibilização de ferramentas aos alunos que permitam o acompanhamento dos conteúdos ofertados bem como a realização de avaliações durante o período da autorização de que trata o caput.

Art. $2^{\circ}, \S 1^{\circ}$ As atividades acadêmicas suspensas deverão ser integralmente repostas para fins de cumprimento dos dias letivos e horas-aulas estabelecidos na legislação em vigor.

$\S 2^{\circ}$ As instituições poderão, ainda, alterar o calendário de férias, desde que cumpram os dias letivos e horas-aula estabelecidos na legislação em vigor.

A Portaria 343/2020 autoriza a substituição de aulas presenciais por "aulas" ou "atividades" por meios e tecnologias de informação e comunicação e flexibiliza os 200 dias letivos, previstos na LDB $n^{\circ}$ 9.394/96, artigo 24, inciso I, admitindo-se o cumprimento de 180 dias, para as escolas privadas e públicas. Não se trata aqui de execrar o uso das tecnologias de informação e comunicação na educação, nem da Educação a Distância como modalidade que tem o seu valor para atender a determinadas situações, contextos, regiões e sujeitos. Importa, portanto, destacar o entendimento de EaD como

modalidade na qual a mediação didático-pedagógica, nos processos de ensinoaprendizagem, ocorre com a utilização de meios e tecnologias de informação e comunicação, envolvendo estudantes e profissionais da educação (professores, tutores e gestores), que desenvolvem atividades educativas em lugares e ou tempos diversos. Os 
meios podem ser: material impresso, digital, televisivo, radiofônico, áudio, vídeo, de forma online ou off-line (CAMPANHA NACIONAL PELO DIREITO À EDUCACÃO, 2020, p. 5).

O processo didático-pedagógico mediado ou não pelas tecnologias não prescinde de um ensino personalizado que se efetiva pelo professor na relação com os estudantes. É ele o responsável pela organização didática do processo de ensino que se concretiza de forma presencial-física e ou virtual-online. Em todas as situações essa organização requer a relação professor-aluno, objetivo-avaliação, conteúdo-método/técnicas de ensino, tempo-espaço de ensino-aprendizagem. É a articulação desses elementos em plano didático e o uso consciente pelo professor dos recursos tecnológicos como ferramentas pedagógicas (VASCONCELOS, 2020, p. 153) que possibilitam o alcance das finalidades educativas e dos objetivos de aprendizagem previstos no currículo escolar.

Entretanto, a forma como a utilização de meios e tecnologias de informação e comunicação, e o ensino on-line foram apresentados aos professores, estudantes e suas famílias durante a pandemia do Covid-19, caracterizou-se por ações improvisadas sem a formação docente e com delegação de responsabilidades. Para compreender como as famílias se percebem partícipes desse processo, realizou-se uma pesquisa de abordagem qualitativa com uso de dados quantitativos, ${ }^{\text {viii }}$ com aplicação de 327 questionários no Google Forms ${ }^{i x}$. Desses, 291 respondentes são do sexo feminino e 36 do sexo masculino, 316 na faixa etária 30 a 66 anos e 11 na faixa de 18 a 29 anos.

Perguntou-se aos respondentes sobre suas percepções acerca do acompanhamento de crianças e adolescentes na realização de atividades usando Tecnologias da Informação e Comunicação (TIC). Algumas respostas são apresentadas no quadro 1 - Acesso à internet e tecnologias, sendo os participantes identificados por $(\mathrm{R})$ seguido do número.

Quadro 1 - Acesso à internet e tecnologias

\section{Acompanhamento de atividades remotas usando Tecnologias da Informação e Comunicação}

Sinal de internet lenta. (R9)

A falta de um ambiente virtual melhor formatado especificamente para a educação em casa. (R10)

Necessidade de impressão de atividades. (R16)

Ficar à disposição durante a aula online para auxiliar nas dúvidas sobre a ferramenta utilizada. (R42)

Participar de várias reuniões online com duas crianças (2 e 5 anos) querendo minha atenção. (R45)

Acompanhar a aula e os questionamentos dos colegas que acontecem ao mesmo tempo, porém através da tela do computador ou do celular fica mais dificil. (R48)

Pouco computador em casa. Somos 5 que precisam e Temos apenas 2 computadores. (R142)

Acho bacana, porque tenho acesso as tecnologias, porém me

A escola deve ser o espaço de ensino-aprendizagem, mas deve incluir mais a família no processo. (R5)

A escola é o espaço que assegura não apenas a socialização de conhecimentos acumulados pela humanidade, mas promove a interação social e o desenvolvimento integral dos estudantes. (R13)

A escola atual está defasada. (R19)

Acredito que as escolas precisam ter mais sensibilidade e cuidado com os estudantes e as famílias, porém considero um espaço riquíssimo de convivência e aprendizado. (R34)

A escola presencial não pode ser substituída. As crianças precisam ter vínculos de amizade, brincar, respeitar as diferenças e saber "sobreviver" aos desafios reais. (R39)

Notei que não há preocupação com o aluno, e sim com o conteúdo. (R44) 
preocupa as crianças que não tem a mesma oportunidade. (R19)

O uso de tecnologia dispersa a atenção. Ela tem apenas 4 anos. (R45)

Não gostei, na minha opinião qualquer aluno ou pessoa que estuda precisa de interação sobretudo com pessoas da sua mesma etapa. Tecnologia digital é só uma ferramenta que ajuda ou facilita algumas aulas. (R59)
A escola do meu filho ainda está perdida, sem saber como garantir o ensino à distância. (R54)

O governo deveria investir mais na educação em um modo gera, pois as nossas crianças são o futuro desse País. (R61)

Escola é vida. Não só forma um aluno, mas, também prepara para a vida. (98)

Essencial, porém neste período o ensino a distância é descabido. A maioria não domina as tecnologias elou não tem acesso a elas. (R156)

Quadro elaborado pelas autoras com as respostas do questionário Google Forms, 2020.

Em relação ao acesso à internet e às tecnologias para viabilizar o ensino remoto na educação básica, no contexto da pandemia do Covid-19, as respostas revelam que essa forma de ensinar apresenta

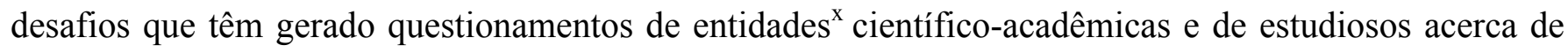
suas repercussões nas aprendizagens dos estudantes. Entre os desafios a serem superados, destaca-se a indisponibilidade ou insuficiência de internet banda larga, computadores e impressoras para atender a mais de uma criança de uma mesma família, nos mesmos horários de atividades. Nessas circunstâncias, a não garantia de condições iguais de acesso infrige o artigo 206, inciso I da Constituição de 1988 que prevê: "o ensino será ministrado com base na igualdade de condições para o acesso e permanência na escola". Dada sua importância, o princípio é reproduzido na LDBEN nº 9.394/96 (art. 3º, I) e na Lei Federal n ${ }^{\circ}$ 8.069, de 13 de julho de 1990, que institui o Estatuto da Criança e do Adolescente (ECA) (art. 53, I) e tem como sentido proporcionar a isonomia entre os estudantes, condição essencial para se promover equidade entre eles.

Ao mesmo tempo, tornou-se perceptível a delegação de responsabilidades às famílias gerando sobrecarga de trabalho, principalmente para as mulheres que, conforme dados da pesquisa, representam $89 \%$ do total de respondentes que assumiram mais um papel, o de acompanhar as crianças nas tarefas escolares por meio remoto. Somam-se a essa atividade, as tarefas domésticas, cuidados com filhos e home office, gerando um fenômeno de intensificação de atividades reservadas às mulheres ${ }^{\mathrm{xi}}$ que suscitam reflexões sobre como as questões de gênero são marcantes em momentos de crise como a da pandemia.

A dispersão da atenção e a dificuldade de concentração das crianças, causadas pela fragilidade ou inexistência de interação com os colegas de turma e com os professores, são também desafios a serem enfrentados pelas redes de ensino e escolas. Considera-se que o ensino remoto infringe a garantia constitucional do direito a educação de qualidade, uma vez que as condições em que ocorre não favorecem o alcance dos objetivos de aprendizagem previstos nos currículos escolares e nos projetos pedagógicos como meios de cumprir as finalidades constitucionais da educação expressas no artigo 205. Em face desses elementos, reflete-se sobre os aspectos básicos da educação escolar, especificamente os 
didático-pedagógicos cuja organização compete ao docente e são objetivados na relação professor-aluno, indispensável à formação dos estudantes.

Assim, cumpre reconhecer as condições socioeconômicas de estudantes e docentes e recolocar as atribuições do Estado de zelar pelas políticas sociais, dentre essas, a política educacional. As condições físicas, materiais e de equipamentos, o financiamento público estatal, as tecnologias digitais e os ambientes adequados de ensino-aprendizagem precisam ser assegurados pelo poder público. Os princípios da gestão democrática, a autoria e autonomia do trabalho docente, são pilares conquistados, intransferíveis e indispensáveis no ato educativo.

Portanto, neste momento de crise do capital e sanitária, cabe às instituições jurídicas e sociais, às associações científicas, entidades sindicais e movimentos populares coibir, defender e lutar para que, sob nenhum pretexto, os direitos sejam driblados, encurtados e encobertos.

\section{Desafios e questões finais}

Sucessivas crises do capital têm levado Estado e mercado a criar, expandir e regular outros nichos, que antes eram serviços de provisão estatal. Nesse sentido, as discussões sobre a EaD, sobretudo na educação básica, antecedem a pandemia, que configura-se como oportunidade para mercadores e corporações com interesses na abertura desse mercado educacional e do setor tecnológico, mídias e informática.

O Governo Federal e autoridades adotam medidas regulatórias, de gestão e pedagógicas à luz do Decreto n. ${ }^{\circ}$ 9.057/2017 que trata da EaD, e da Portaria $n^{\circ} 343 / 2020$, que dispõe e flexibiliza 200 dias letivos e autoriza oferta de disciplinas presenciais na modalidade a distância para estudantes de educação básica pública, favorecendo a atuação do setor privado lucrativo dentro do setor público.

Nas condições de aceleração e utilização das tecnologias, como garantir ao estudante o direito à Educação? E ao conhecimento científico produzido? Na defesa da educação pública e democrática confirma-se a necessidade de atuação coletiva do Estado e da sociedade para:

- Reafirmar a educação pública como direito universal, humano e social de todos.

- Garantir condições materiais, equipamentos para democratizar o acesso à internet com banda larga para todos os estudantes da escola pública.

- Adotar as tecnologias como instrumentos para melhorar a qualidade da educação, potencializando processos de ensino-aprendizagem por meio de metodologias e linguagens, sem substituição do professor. 
- Garantir a autoria e autonomia docente para selecionar e organizar conteúdos curriculares e pedagógicos a serem trabalhos com mediação de tecnologias virtuais e presenciais, impedindo a entrada de pacotes prontos e padronizados.

- Defender a natureza e especificidade da escola pública, coibindo qualquer tentativa de torná-la semelhante a empresa comercial em suas finalidades e processos.

$\mathrm{Na}$ construção da resistência ativa da comunidade escolar, detentora de outras proposições e alternativas viáveis, consoantes com a sua realidade, não se pode desconsiderar as ideologias e interesses por trás do advento das tecnologias em contexto da pandemia. Entretanto, não se pode admitir retrocessos, driblagens e encurtamento do direito educacional de grupos sociais populares. Assim, uma vez instituída a educação a distância na legislação, essa deve vir acompanhada de condições materiais, intelectuais e tecnológicas para concretizá-la de fato e de direito.

\section{REFERÊNCIAS}

ALVES, Giovanni. O que é precariado Blog da Boitempo. 20 maio 2013. Disponível em: https://blogdaboitempo.com.br/category/colunas/giovanni-alves/ Acesso em fevereiro 2020.

ANTUNES, Ricardo. Adeus ao trabalho?: ensaio sobre as metamorfoses e a centralidade do mundo do trabalho. São Paulo: Cortez, 2015. 2018.

O privilégio da Servidão: o novo proletariado de serviços na era digital. São Paulo: Boitempo,

APPLE, Michael. Educando à direita: mercados, padrões, Deus e desigualdade. São Paulo: Cortez: Instituto Paulo Freire, 2003.

BRASIL. Constituição da República Federativa do Brasil de 1988. Brasileira, DF: Senado Federal. 2013.

. Conselho Nacional de Educação - CEB - Parecer no 15, de 03 de novembro de 1997. Consulta sobre ensino fundamental e médio (supletivo) com utilização e metodologia de ensino a distância. Câmara de Educação Básica. Diário Oficial da União. Brasília, DF, 16 jan. 1998.

. Conselho Nacional de Educação - CEB - Parecer no 41/2002 -Institui Diretrizes Curriculares Nacionais para a Educação a Distância na Educação de Jovens e Adultos e para a Educação Básica na etapa do Ensino Médio. Diário Oficial da União: Seção 1. Brasília, DF, 24 dez. 2002. p. 167.

- Conselho Nacional de Educação - Câmara de Educação Básica - Resolução $n^{o} 1$, de 2 de

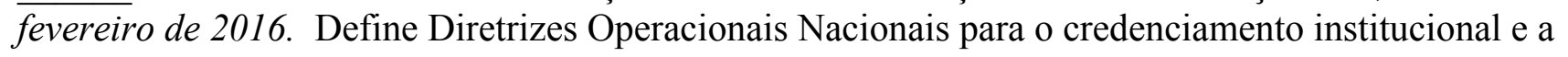
oferta de cursos e programas de Ensino Médio, de Educação Profissional Técnica de Nível Médio e de Educação de Jovens e Adultos, nas etapas do Ensino Fundamental e do Ensino Médio, na modalidade Educação a Distância, em regime de colaboração entre os sistemas de ensino. 2016.

. Conselho Nacional de Educação CEB-Parecer CNE-CEB $n^{\circ} 13 / 2015$. Reexame do Parecer $\overline{\mathrm{CNE} / \mathrm{CEB}} \mathrm{n}^{\circ} 2 / 2015$, que reexaminou o Parecer CNE/CEB no $12 / 2012$, que define Diretrizes 
Operacionais Nacionais para a oferta de Educação a Distância (EAD), no âmbito da Educação Básica, em regime de colaboração entre os Sistemas de Ensino. 2015

. Conselho Nacional de Educação /Câmara de Educação Básica e Fórum Nacional dos Conselhos Estaduais de Educação (FNCEE). Reexame do Parecer CNE/CEB $n^{\circ} 2 / 2015$, que define Diretrizes Operacionais Nacionais para a oferta de Educação a Distância (EAD), no âmbito da Educação Básica, em regime de colaboração entre os Sistemas de Ensino. PARECER Homologado e publicado no D.O.U. de 28/1/2016, Seção 1, pág. 19. 2016.

. Decreto $n^{\circ} 9.057$, de 25 de maio de 2017. Regulamenta o art. 80 da Lei no 9.394, de20 de dezembro de 1996, que estabelece as diretrizes e bases da educação nacional. Diário Oficial da União. Atos do Poder Executivo. Edição 100, seção 1, p. 3.26 de maio de 2017.

. Decreto Legislativo $n^{\circ} 6$ de 20 de março de 2020. Dispõe sobre o estado de calamidade pública, nos termos da solicitação do Presidente da República encaminhada por meio da Mensagem nº 93, de 18 de março de 2020.

. Emenda Constitucional $n^{\circ}$ 95, de 2016. Altera o Ato das Disposições Constitucionais Transitórias, para instituir o Novo Regime Fiscal, e dá outras providências. Brasília, DF, 2016. Disponível em: https://www2.camara.leg.br/legin/fed/emecon/2016/emendaconstitucional-9515dezembro-2016-784029-publicacaooriginal-151558-pl.html. Acesso: 11 de jun. 2020.

. Lei $n^{\circ}$ 8.069, de 13 de julho de 1990. Estatuto da Criança e do Adolescente. Brasília, DF, 1990.

. Lei $\mathrm{n}^{\circ}$ 9.394, de 20 de dezembro de 1996. Estabelece as diretrizes e bases da educação nacional. Diário Oficial da União. Brasília, DF, 21 jul. 2014.

. Lei $n^{0} 11.079$, de 30 de dezembro de 2004. Institui normas gerais para licitação e contratação de parceria público-privada no âmbito da administração pública. Diário Oficial da União: Seção 1. Brasília, DF, 31 dez. 2004. p. 6.

. Medida Provisória $n^{\circ}$ 927, de 22 de março de 2020. Dispõe sobre as medidas trabalhistas para enfrentamento do estado de calamidade pública reconhecido pelo Decreto Legislativo ${ }^{\circ} 6$, de 20 de março de 2020, e da emergência de saúde pública de importância internacional decorrente do coronavírus (covid-19), e dá outras providências.

. Medida Provisória $n^{\circ}$ 936, de 01 de abril de 2020. Institui o Programa Emergencial de Manutenção do Emprego e da Renda e dispõe sobre medidas trabalhistas complementares para enfrentamento do estado de calamidade pública reconhecido pelo Decreto Legislativo $\mathrm{n}^{\circ} 6$, de 20 de março de 2020, e da emergência de saúde pública de importância internacional decorrente do coronavírus (covid-19), de que trata a Lei no 13.979, de 6 de fevereiro de 2020.

Portaria $n^{\circ} 343$, de 17 de março de 2020. Dispõe sobre a substituição das aulas presenciais por aulas em meios digitais enquanto durar a situação da pandemia do Novo Coronavírus - COVID-19. Ministério da Educação. Diário Oficial da União. Brasília, DF, 18 mar. 2020.

. INEP - Instituto Nacional de Pesquisas Educacionais. Censo da Educação Básica - 2019. Brasília: Resumo Técnico, 2020.

CAMPANHA NACIONAL PELO DIREITO À EDUCAÇÃO. Guia Covid-19: educação a distância. EaD. Brasília, 2020. v. 3. Disponível em: www.campanha.org.br. Acesso em: 18 maio 2020. 
CUNHA, Luiz Antônio. A Educação Brasileira na Primeira Onda Laica: do Império à República. 2017. Disponível: http://www.luizantoniocunha.pro.br/\#.Acesso em: 15 fev. 2020.

CURY, Carlos Roberto Jamil. Direito à educação, escravatura e ordenamento jurídico no Brasil Império. Cadernos de História da Educação, v.19, n.1, p.110-148, jan./abr. 2020.

ESPINOZA, Betty Solano; QUEIROZ, Felipe Campanuci. Campanuci. Breve análise sobre as redes da Escola sem Partido. In: FRIGOTTO, G. (org.). Escola "sem" Partido: Esfinge que ameaça a educação e a sociedade brasileira. Rio de Janeiro, RJ: UERJ, LPP. 2017.

FERNANDES, Florestan. A revolução burguesa no Brasil. 5.ed. São Paulo: Globo, 2006.

GUEDES, Paulo. Exposição de motivos n. 008/2020. Disponível em:

http://www.planalto.gov.br/ccivil_03/_Acesso em 09 abr. 2020.

HARVEY, David. Política anticapitalista em tempos de covid-19. In. DAVIS, Mike. et al. Coronavírus e a luta de classes. Brasil: Terra sem Amos, 2020. p. 13-24.

HOBSBAWN, Eric. Era dos extremos: breve século XX: 1914-1991. São Paulo: Companhia das Letras, 1996.

MARIUTTI, Eduardo Barros. Estado, mercado e concorrência: fundamentos do "neoliberalismo" como uma nova cosmovisão. Revista da Sociedade Brasileira de Economia Política, no 54, set./dez. 2019.

MARX, Karl. Contribuição à crítica da Economia política. São Paulo: Expressão popular, 2008

MARX, Karl; ENGELS, Friedrich. A ideologia alemã. São Paulo: Editora Hucitec, 1984

MASCAVO, Alysson. Estado e forma política. São Paulo:Boitempo, 2013.

MORAES, Moema Gomes; PEIXOTO, Joana. Estado do conhecimento como perspectiva crítica para as pesquisas em educação. Educação e Tecnologias em questão. Revista Reflexão e Ação, v. 25, n. 3, p 321338, set./dez. 2017.

RIBEIRO, Darcy. A universidade necessária. São Paulo, Editora Paz e Terra, 1982.

SENNETT, Richard. A corrosão do caráter: consequências pessoais do trabalho no novo capitalismo. Rio de Janeiro: Editora Record, 2006.

SOARES, André Marcio Neves. Coronavirus, qual o Futuro? Disponível em: https:// aterraeredonda.com.br. Acesso em: 08 abr. 2020.

UNIVERSIDADE DE BRASÍLIA. Relatório do Decanato de Planejamento, Orçamento e Avaliação Institucional sobre a execução orçamentária da Universidade de Brasília do exercício de 2019. Brasília. 2020.

VASCONCELOS, Juliene Silva. Desafios e Particularidades do Trabalho Docente e Tutorial em Cursos a Distância: em busca de sua constituição profissional. Revista Educação e Politicas em Debate, v. 9, n. 1, p. 151 - 168, jan./abr. 2020. 


\footnotetext{
i Professora do Programa de Pós-Graduação em Educação da Faculdade de Educação da Universidade de Brasília (UnB) Brasil. Doutora em Educação pela Universidade Estadual de Campinas. Brasília. Brasil. E-mail: abadia.unb@gmail.com ORCID http://orcid.org/0000-0001-6048-077X

ii Professora do Programa de Pós-Graduação em Educação da Faculdade de Educação da Universidade de Brasília (UnB) Brasil. Doutora em Educação pela Universidade de Brasília. Brasília. Brasil. E-mail: edileuzafeunb@gmail.com. ORCID http://orcid.org/0000-0002-9837-2958

${ }^{\text {iii }}$ Relatório da OXFAM Tempo de cuidar: o trabalho de cuidado não remunerado e mal pago e a crise global da
} desigualdade. 19 jan. 2020. Disponível em:https://oxfam.org.br/noticias/bilionarios-do-mundo-tem-mais-riqueza-do-que-60da-populacao-mundial/. Acesso em: 09 abr. 2020.

${ }^{\text {iv }}$ A Escola sem Partido é um movimento político conservador, idealizado no início dos anos 2000 e propalado como de natureza "apartidária", com o argumento de representar pais e estudantes contrários ao que caracterizam "doutrinação ideológica" nas escolas (ESPINOZA; QUEIROZ, 2017)

${ }^{v}$ GUEDES, P. R. N. Exposição de Motivos $n^{\circ}$ 0008/2020. Disponível em: http://www.planalto.gov.br/ccivil_03/_Acesso em: 09 abr. 2020.

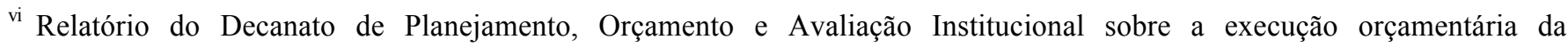
Universidade de Brasília do exercício de 2019-2020.

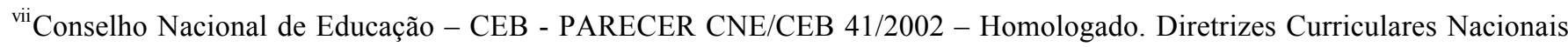
para a Educação a Distância na Educação de Jovens e Adultos e para a Educação Básica na etapa do Ensino Médio. Diário Oficial da União de 24/12/2002, Seção 1, p. 167.

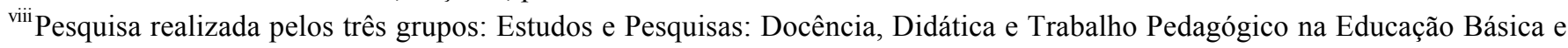
Superior (Prodocência); Estudos e Pesquisas sobre Organismos Internacionais, Gestão e Políticas para Educação Básica (Águia); e o Estudos e Pesquisas sobre Formação e Atuação de Professores/Pedagogos (Gepfape), todos da Faculdade de Educação da Universidade de Brasília (UnB).

${ }^{\mathrm{ix}}$ Disponível em: https://forms.gle/xhverFBmCxTqMzNAG7.

x Disponível em: https://avaliacaoeducacional.com/2020/05/03/pais-e-professores-ensino-remoto-nao-e-dia-letivo/ ehttps://www.anped.org.br/news/manifesto-anped-educacao-distancia-na-educacao-infantil-nao

${ }^{x i}$ Disponível em: https://www.nexojornal.com.br/expresso/2020/03/24/Quais-os-impactos-da-pandemia-sobre-as-mulheres 